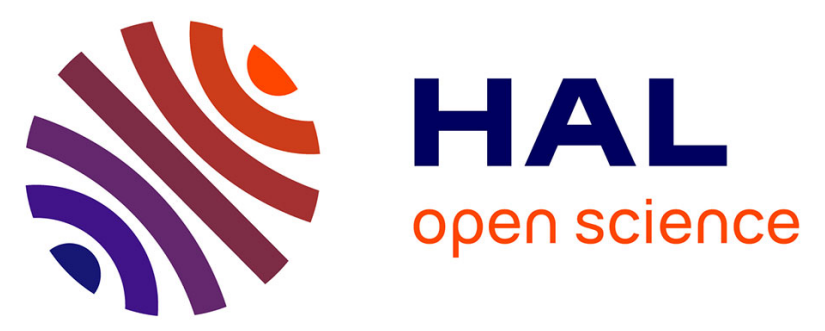

\title{
Poly( ortho -phenylenediamine) overlaid fibrous carbon networks exhibiting a synergistic effect for enhanced performance in hybrid micro energy storage devices
}

Halim El Mahdi, Rezan Demir-Cakan, Catherine Debiemme-Chouvy, Hubert

Perrot, Mama El Rhazi, Ozlem Sel

\section{To cite this version:}

Halim El Mahdi, Rezan Demir-Cakan, Catherine Debiemme-Chouvy, Hubert Perrot, Mama El Rhazi, et al.. Poly ( ortho -phenylenediamine) overlaid fibrous carbon networks exhibiting a synergistic effect for enhanced performance in hybrid micro energy storage devices. Journal of Materials Chemistry A, 2021, 9 (16), pp.10487-10496. 10.1039/d1ta00763g . hal-03223866

\section{HAL Id: hal-03223866 \\ https: / hal.sorbonne-universite.fr/hal-03223866}

Submitted on 11 May 2021

HAL is a multi-disciplinary open access archive for the deposit and dissemination of scientific research documents, whether they are published or not. The documents may come from teaching and research institutions in France or abroad, or from public or private research centers.
L'archive ouverte pluridisciplinaire HAL, est destinée au dépôt et à la diffusion de documents scientifiques de niveau recherche, publiés ou non, émanant des établissements d'enseignement et de recherche français ou étrangers, des laboratoires publics ou privés. 


\title{
Poly(ortho-phenylenediamine) overlaid fibrous carbon networks exhibiting synergistic effect for enhanced performance in hybrid micro energy storage devices
}

\author{
El Mahdi Halim ${ }^{a, b}$, Rezan Demir-Cakan ${ }^{c, d}$, Catherine Debiemme-Chouvya, Hubert Perrot ${ }^{a}$, Mama El \\ Rhazi $^{\mathrm{b}}$ and Ozlem Sel ${ }^{\mathrm{a}, *}$

\begin{abstract}
Nanostructured fibrous composite electrodes are prepared by direct electrooxidation of ortho-phenylenediamine (oPD) monomer on a carbon network based on single-wall carbon nanotubes (SWCNT). The simple and rapid fabrication method leads to the formation of a nanofibrous composite electrode, where poly(ortho-phenylenediamine) (PoPD) layer envelops a previously formed carbon network, which is prepared with various SWCNT/PoPD ratios. Excellent cycling stability for more than 10000 cycles is achieved for SWCNT/PoPD (wt/wt ratio of 1:5) in an asymmetric two-electrode configuration (in which $\mathrm{Zn}$ is used as both reference and counter electrodes) with a specific capacitance of about $350 \mathrm{~F} \cdot \mathrm{g}^{-1}\left(35 \mathrm{mF} \cdot \mathrm{cm}^{-2}\right)$ at $7.3 \mathrm{~A} \cdot \mathrm{g}^{-1}$ $\left(0.73 \mathrm{~mA} \cdot \mathrm{cm}^{-2}\right)$ current density. This performance is about 3 times higher than that of the PoPD $\left(110 \mathrm{~F} \cdot \mathrm{g}^{-1}\right)$ electrode and $~$ 30 times than that of bare carbon network $\left(12 \mathrm{~F} \cdot \mathrm{g}^{-1}\right)$. The improved performance of the nanocomposite compared to those of its pristine counterparts is ascribed to a synergistic effect between SWCNT and PoPD, enhanced electrical conductivity and as well as to the resulting open porous network structure allowing the easy access of the electrolyte ions into the electrode. This device structure with a capacitor-type nanocomposite cathode can be of interest for micro-energy storage devices and for sytems employing other charge carriers.
\end{abstract}

\section{Introduction}

Development of green technologies for energy conversion and storage has attracted significant interest for producing and storing renewable energy with the ultimate goal of tackling the environmental problems caused by the fossil fuels. Among these technologies, supercapacitors represent one of the most attractive energy storage devices, which deservedly received attention due to its excellent power density, long cycle life and fast charge/discharge rate..$^{1-4}$

Carbon based materials such as actived carbon, graphene (Gr) and carbon nanotubes (CNT) have largely been studied as electrode materials for electric double layer capacitors (EDLC) due to their attractive characteristics, such as high surface area, good mechanical and chemical stability. 1, 5, 6 Moreover, the high porosity of the structure allows an easy access of electrolyte ions within the electrode. CNTs have been considered as one of the promising electrode materials for the next generation of high power energy storage, ${ }^{7-9}$ which exhibit a non-faradic energy storage capability while offering high surface area benefits. However, they exhibit a relatively low specific capacitance which limit their applications. Nevertheless, CNTs present remarkable properties such as good conductivity, strength and stiffness, which maintain the interest for their use as reinforcements for the generation of multifunctional composites. ${ }^{10}$ For instance, forming a CNT/conducting polymer (CP) composite has been considered not only to improve the specific capacitance of CNTs but also to overcome the drawbacks of CPs, especially, their poor cycling stability caused by the swelling/shrinkage during the repetitive charge-discharge processes. CPs themselves have also been widely employed as pseudocapacitive electrode materials due to their low cost, good electrical conductivity and relatively high specific capacitance..$^{11-15}$

Polypyrrole (PPy) and polyaniline (PANI) based electrodes are shown to exhibit excellent specific capacitance values reaching $400 \mathrm{~F} \cdot \mathrm{g}^{-1},{ }^{14}$, 16-19 which is larger than that of the carbon nanomaterials. However, their cycling instability remains one of the major issue to get the full benefit of these pseudocapacitive CPs. Liu et al. ${ }^{14}$ discussed the stability of PPy and PANI nanowire based electrodes for supercapacitors and reported that only $\sim 50 \%$ of their capacitance can be retained after 1000 cycles. The research efforts evolve in the direction of the protecting the $\mathrm{CP}$ based electrodes for example by a carbonaceous shell, 14,20 especially to alleviate swelling and shrinking during cycling and thus to enhance the cycling stability.

In this perspective, the combination of carbon nanotubes with conducting polymers has become a promising approach leading to a nanocomposite with enhanced electrochemical properties. In addition, this configuration may offer a strong synergistic effect, which improves the capacitive properties regarding the specific capacitance values and the cycling stability. Various conducting polymer/carbon material composites have been studied such as $\mathrm{PPy} / \mathrm{CNT}$, ${ }^{14}, 21-23 \mathrm{PANI} / \mathrm{CNT}$, ${ }^{24-26}$ poly(3,4-ethylenedioxythiophene) (PEDOT)/CNT, ${ }^{27-29} \mathrm{PANI} / \mathrm{Gr},{ }^{30,} 31$ and PPy/Gr. ${ }^{32-34}$ Cherusseri et al. showed that oxidized-carbon nanotubes/PPy nanocomposite exhibits a specific capacitance of about $80 \mathrm{~F} \cdot \mathrm{g}^{-1}$ at a current density of $7 \mathrm{~mA} \cdot \mathrm{cm}^{-2} \cdot{ }^{35}$ Cong et al. fabricated PANI nanorods by electropolymerization on graphene paper, the resulting composite exhibited high electrical conductivity, good flexibility and good synergistic effect between graphene and PANI leading to a high specific capacitance of about $760 \mathrm{~F} \cdot \mathrm{g}^{-1}$ with the retention of $82 \%$ after 1000 cycles. ${ }^{36}$ It is noted that pristine PANI film tested under the 
same conditions presented only $52 \%$ of capacity retention. Recently, Tahir et al. reported a high-performance micro-SCs based on PEDOTcoated MWCNT nanoporous network. This composite microelectrode exhibited a maximum specific capacitance of $20.6 \mathrm{mF} \cdot \mathrm{cm}^{-2}$ at $0.1 \mathrm{~mA} \cdot \mathrm{cm}^{-2}$ and retained $99.9 \%$ of its initial capacitance after $20000 \mathrm{CV}$ cycles in a polyvinylalcohol (PVA)/ $\mathrm{H}_{2} \mathrm{SO}_{4}$ gel electrolyte, which was explained by the fact that the open porous structure of CPs and the CNT network allows electrolyte ions to diffuse from the surface of the electrode into their interior. ${ }^{27}$

As an extension to the developments achieved on the most researched CPs, a subsequent path is to scrutinize the structural effects of their derivatives. In this respect, aromatic diamine polymers like poly(ortho-phenylenediamine) (PoPD) has deservedly received attention due to the active free amino and imino groups present in their structure, which provide structural modification possibility. ${ }^{37}$ PoPD has been widely combined with graphene or carbons to form nanocomposite electrodes for supercapacitor applications, ${ }^{38-42}$ satisfactory specific capacitances have been obtained. However, the cycling stability of these composites was poor and often tested for only 1000 or 1500 cycles, except from limited number of reports, ${ }^{38}$ providing information about the long term electrode stability. For the latter, Yang et al. deposited PoPD on graphene via in situ polymerization, and tested as electrode material for supercapacitors. A synergistic effect was noticed which resulted in a high specific capacitance of about $381 \mathrm{~F} \cdot \mathrm{g}^{-1}$ in $1 \mathrm{M} \mathrm{H}_{2} \mathrm{SO}_{4}$ electrolyte at $1 \mathrm{~A} \cdot \mathrm{g}^{-1}$ and a retention of $90 \%$ of the initial capacitance after 5000 cycles. $^{38}$

Herein, we exploit the aromatic diamine polymer, i.e. poly(orthophenylenediamine) and adopted a strategy that PoPD layer envelops a previously formed carbon network, leading to a carbon/PoPD nanofibrous composite electrode. The rationale behind this strategy is that the PoPD layer alone shows a relatively high cycling stability, ${ }^{43}$ but with a modest specific capacitance value. The latter is attributed to a relatively low electronic conductivity and it has been expected to be enhanced with a subjacent carbon network. Then, a nanostructured fibrous composite electrode was fabricated by a simple and rapid strategy through electropolymerization of OPD on an electrode modified by a network composed of SWCNT and poly(vinylidene fluoride-hexafluoropropylene) (PVDF-HFP). A dispersion of SWCNT/PVDF-HFP was deposited on the both gold (for three-electrode cell tests) and graphite (for two-electrode Swagelok cell tests) electrodes, followed by electropolymerization of oPD using cyclic voltammetry. The compositional and the morphological characterizations of the nanocomposite were carefully investigated prior to the electrochemical tests. The capacitive performances of SWCNT/PoPD nanocomposite networks as electrode materials for supercapacitors were evaluated in aqueous $\mathrm{NaCl}$ electrolyte using both three and two-electrode cell configurations. Different mass ratios between SWCNT and POPD were tested in order to investigate the optimized SWCNT/PoPD composition in terms of capacitive performance. Excellent cycling stability upon 11000 cycles was achieved for SWCNT/PoPD (wt/wt ratio of 1:5) in an asymmetric twoelectrode configuration with a specific capacitance of about $350 \mathrm{~F} \cdot \mathrm{g}$ $1\left(35 \mathrm{mF} \cdot \mathrm{cm}^{-2}\right)$ at $7.3 \mathrm{~A} \cdot \mathrm{g}^{-1}\left(0.73 \mathrm{~mA} \cdot \mathrm{cm}^{-2}\right)$ current density. The improved performance of the nanocomposite compared to those of its pristine counterparts is ascribed to a synergistic effect between SWCNT and PoPD, enhanced electrical conductivity and as well as to the resulting open porous network structure. The developments achieved in the charge storage properties are significant and the SWCNT/PoPD nanocomposite thin film electrodes exhibit desirable (electro)chemical attributes which can be of interest for microenergy storage devices and for systems employing other charge carriers such as aqueous $\mathrm{Zn}$ ion batteries. ${ }^{27,44-47}$

\section{Experimental part}

2.1. Electrode Preparation: 90 wt. \% of SWCNT powder (length: 300-2300 nm and diameter: 0.7-1.1 nm, Sigma-Aldrich-704121) and 10 wt. \% of PVDF-HFP polymer (poly(vinylidene fluoridehexafluoropropylene)), (Sigma-Aldrich) were dispersed in NMP (Nmethyl-2-pyrrolidone). Typically, a dispersion containing $0.9 \mathrm{mg}$ SWCNT (BET (Brunauer, Emmett and Teller) surface area of $842 \mathrm{~m}^{2} \cdot \mathrm{g}$ $\left.{ }^{1}\right)^{48}$ and $0.1 \mathrm{mg}$ PVDF-HFP in $5 \mathrm{~mL} \mathrm{NMP} \mathrm{is} \mathrm{prepared.} \mathrm{A} 10 \mu \mathrm{L}$ portion of this dispersion was drop-cast on the gold electrodes $\left(0.2 \mathrm{~cm}^{2}\right)$ or graphite electrodes $\left(\sim 50 \mathrm{LL}\right.$ for $\left.1 \mathrm{~cm}^{2}\right)$ and dried for $2 \mathrm{~h}$ at $120{ }^{\circ} \mathrm{C},{ }^{49}$ this SWCNT/PVDF-HFP electrode is called SWCNT modified electrode thereafter (corresponding to the carbon network on Figure 1a). The electrochemical polymerization of OPD was performed on SWCNT modified electrodes (gold or graphite) using three-electrode configuration, in which, a SWCNT modified electrode as working electrode, $\mathrm{Ag} / \mathrm{AgCl}(3 \mathrm{M} \mathrm{KCl}$ saturated with $\mathrm{AgCl}$ ) as reference electrode and a platinum grid as counter electrode were used. The oPD monomer (1,2-diaminobenzene, Sigma-Aldrich) was dissolved in a $0.1 \mathrm{M} \mathrm{H}_{2} \mathrm{SO}_{4}$ solution to reach a final oPD concentration of $5 \mathrm{mM}$. The electropolymerization of oPD monomer is performed using cyclic voltammetry (CV) from -0.35 to $0.8 \mathrm{~V} \mathrm{vs} \mathrm{Ag} / \mathrm{AgCl}$ at a scan rate of 50 $\mathrm{mV} \cdot \mathrm{s}^{-1}$ (Figure 1b).

In order to optimize the composition of SWCNT/PoPD nanocomposite, several mass ratios between SWCNT and PoPD have been studied. The mass ratio has been varied by increasing the number of the electropolymerization cycles of OPD, while the SWCNT mass was kept constant for all the ratios studied. The mass ratio was evaluated using quartz crystal microbalance (QCM) by measuring the resonant frequency of the quartz crystal $(9 \mathrm{MHz}, \mathrm{AWS}$, Spain) $(\Delta f)$ before and after the deposition of SWCNT and of POPD on goldcoated quartz crystal resonators. The $\Delta f$ is then converted into the mass change $(\Delta m)$ by the Sauerbrey equation $\left(\Delta f_{m}=-k_{s} \cdot \Delta m\right)$ where $k_{s}$ 
a

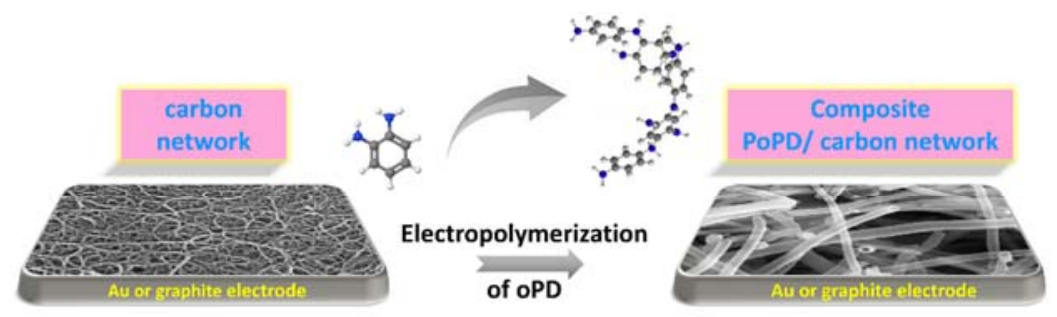

b

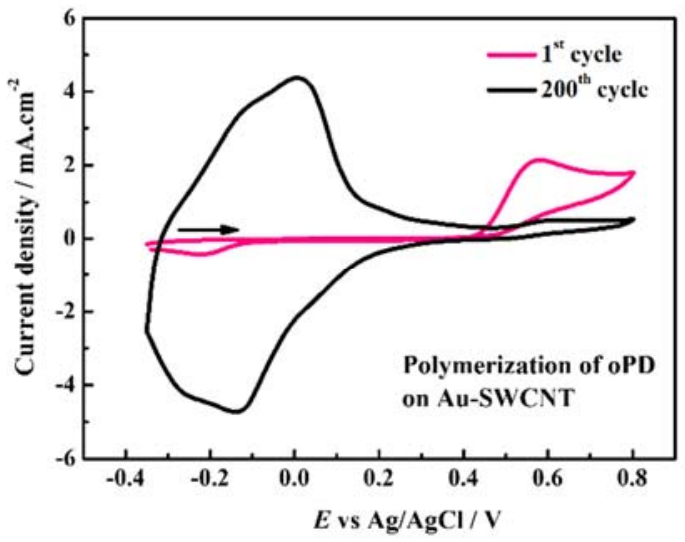

Figure 1. a) Schematic description of the SWCNT/PoPD nanocomposite electrode preparation. 1,2-diaminobenzene (oPD monomer) is electropolymerized on a carbon network made of SWCNTs, leading to SWCNT/PoPD composite. b) The electropolymerization of oPD on SWCNT modified gold electrode, leading to SWCNT/PoPD composite $\left(1^{\text {st }}\right.$ and $200^{\text {th }}$ cyclic voltammetry curves are shown, at $50 \mathrm{mV} \cdot \mathrm{s}^{-1}$ in a solution of $\mathrm{H}_{2} \mathrm{SO}_{4}(0.1 \mathrm{M})$ and oPD monomer (5 mM)).

is the experimental sensitivity coefficient of a resonator operating at $9 \mathrm{MHz} .^{50,51}$

The same electropolymerization method was used to synthesize SWCNT/PoPD nanocomposite on graphite plates $\left(\sim 1 \mathrm{~cm}^{2}\right)$ (maintaining the mass ratio optimized on the gold electrode of the quartz resonator) for the tests in two-electrode Swagelok cells (see Section 2.3). For comparison purposes, the electrochemical polymerization of OPD without SWCNT addition has been pursued in a similar manner as described above. ${ }^{43}$

2.2. Morphological Characterization: The surface morphology of the SWCNT/PoPD films was characterized by a field emission gun scanning electron microscope (FEG-SEM, Zeiss, Supra 55). Transmission electron microscopy analysis was performed by using a JEOL, JEM-1011 electron microscope. X-ray photoelectron spectroscopy analyses were performed using a K-alpha spectrometer (Thermo Scientific) equipped with a monochromatized Al anode (1486.6 eV) and using a pass energy of $100 \mathrm{eV}$ and $20 \mathrm{eV}$, for acquisition of the survey and high-resolution spectra, respectively. The atomic concentration of the surface $(\approx 10 \mathrm{~nm})$ of the samples was calculated after subtraction of the background using Shirley method. ${ }^{52}$ Fourier-transform infrared spectroscopy (FTIR) was performed using an ATR-FTIR instrument (Perkin Elmer Spectrum $400 \mathrm{FT}-\mathrm{IR} / \mathrm{FT}-\mathrm{NIR}$ Spectrometer) in the range of $4000-400 \mathrm{~cm}^{-1}$.

2.3. Electrochemical measurements: The electrochemical performances of SWCNT, POPD and SWCNT/POPD electrodes were investigated using two-electrode and three-electrode configurations in $0.5 \mathrm{M} \mathrm{NaCl}$ salt containing electrolyte and $\mathrm{pH}$ was adjusted to 2 by the addition of $\mathrm{HCl}$. For the three-electrode cell configuration, a platinum grid as a counter electrode, $\mathrm{Ag} / \mathrm{AgCl}$ (3M KCl saturated with $\mathrm{AgCl})$ as reference electrode and modified gold-patterned quartz substrates operating at $9 \mathrm{MHz}$ (AWS, Spain) as working electrode were used. Galvanostatic Charge/Discharge (GCD) measurements were performed in a two-electrode cell configuration, using a classical two-electrode Swagelok-type cell, in which, zinc metal was used as both reference and counter electrodes. As a current collector, $1 \mathrm{~cm}^{2}$ graphite substrate (Graftech, $60 \mu \mathrm{m}$ ) was used for all those three electrode materials namely, SWCNT, PoPD and SWCNT/PoPD. The glass fiber separators (Whatman GF/C with areal weight and thickness of $4.7 \mathrm{mg} \cdot \mathrm{cm}^{-2}$ and $185 \mu \mathrm{m}$, respectively) were used for the measurements in Swagelok cells. GCD tests were also conducted in $0.5 \mathrm{M} \mathrm{NaCl}(\mathrm{pH}=2)$ aqueous solution serving as electrolyte at different current densities. The current applied during electrochemical reduction and oxidation is $7.3 \mathrm{~A} \cdot \mathrm{g}^{-1}$ or $0.73 \mathrm{~mA} \cdot \mathrm{cm}^{-2}$ (the mass loading of the SWCNT/PoPD is $0.1 \mathrm{mg} \cdot \mathrm{cm}^{-2}$ ).

\section{Results and discussion}

\subsection{SWCNT/PoPD nanocomposite films preparation and composition optimization}

3.1.1. Electrochemical synthesis of PoPD on SWCNT modified electrodes: Figure 1 describes the preparation method of the nanocomposite electrodes. A SWCNT network is formed on the conducting substrate (Au electrode or graphite). The SWCNT modified electrode is subsequently coated with PoPD by employing an electrochemical synthesis method (Figure 1), leading to the SWCNT/PoPD nanocomposite. The CV curve in Figure 1 corresponds to the electrosynthesis that presents the oxidation peak of the oPD monomer during the first scan (at $0.55 \mathrm{~V}-0.65 \mathrm{~V}$ vs $\mathrm{Ag} / \mathrm{AgCl}$ ). While the intensity of this peak gradually decreases upon cycling, the redox peaks of the PoPD polymer (situated in the more cathodic potential range) become more intense. The $200^{\text {th }}$ cycle of the voltammograms in Figure 1 depicts that polymerization of the PoPD is successful. It is also noted that the evolution of the $\mathrm{CV}$ response during electropolymerization of PoPD is in agreement with the earlier reports. ${ }^{53,54}$

3.1.2 Optimization of composition in the SWCNT/POPD nanocomposite films: The SWCNT/PoPD nanocomposite structure is expected to have an enhanced electrical conductivity, i.e.; an ameliorated electron percolation in the nanocomposite benefiting from the SWCNT network is intimately related to the resulting electrochemical charge storage properties. To define an optimized SWCNT/PoPD composition in terms of electrochemical properties, several nanocomposites were fabricated with different SWCNT/PoPD mass ratios, (i.e.; $3: 1 ; 1: 2 ; 1: 4 ; 1: 5$ corresponding to 20; 50; 150; $200 \mathrm{CV}$ cycle numbers of electropolymerization of OPD, respectively). The ratio between SWCNT and PoPD was adjusted by 

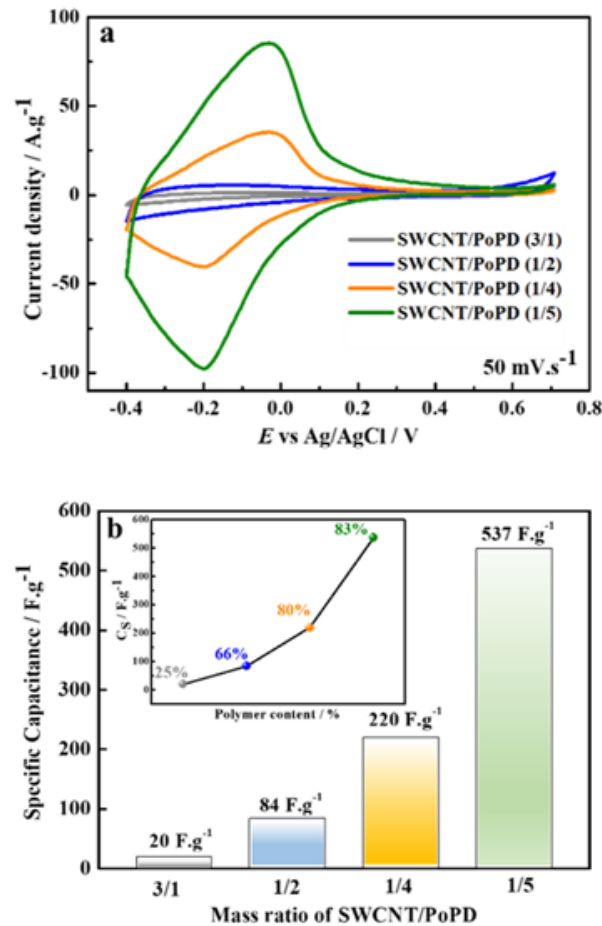

Figure 2. a) CV responses of SWCNT/PoPD nanocomposite thin film as a function of composition (at $50 \mathrm{mV} \cdot \mathrm{s}^{-1}$ ) and b) variation of the specific capacitance of SWCNT/PoPD nanocomposite electrode with different SWCNT/POPD mass ratios. The measurements are performed in $0.5 \mathrm{M} \mathrm{NaCl}$ and $\mathrm{pH}=2$.
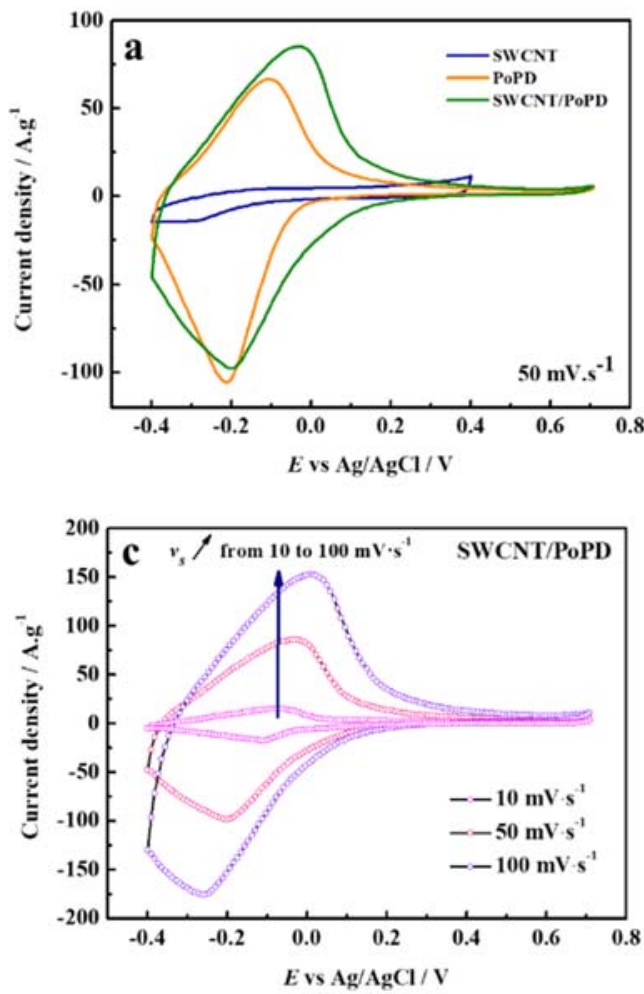

performing the nanocomposite films on the gold electrode of the quartz resonators and by measuring the respective mass variations (related to SWCNT and POPD) by QCM. ${ }^{50}$ Then, the electrochemical performance of these electrodes was investigated by $\mathrm{CV}$ in a potential range from -0.4 to $0.7 \mathrm{~V} \mathrm{vs} \mathrm{Ag} / \mathrm{AgCl}$ in $0.5 \mathrm{M} \mathrm{NaCl}$ at a scan rate of $50 \mathrm{mV} \cdot \mathrm{s}^{-1}$ (Figure 2a). The variation of the mass ratio of SWCNT/PoPD nanocomposite greatly affects the electrochemical behavior and thus the nature of capacitive and faradaic electrochemical responses. One of the extreme composition, in which the SWCNT is dominant (i.e.; SWCNT/PoPD (3:1)), completely prevails over the PoPD redox peaks (Figure 2a). The latter contribution becomes apparent as the PoPD content increases in the nanocomposites that converts to well-defined redox peaks and reaches the highest current intensity for the SWCNT/PoPD with the 1:5 ratio (Figure $\mathbf{2 a}$ ).

The $C_{s}$ values are calculated from the $\mathrm{CV}$ curves in Figure $2 \mathrm{a}$ and using the Eq. 1:

$$
C_{s}=\frac{1}{2 m v\left(E_{2}-E_{1}\right)} \int_{E_{1}}^{E_{2}} I(E) \mathrm{dE}
$$

(Equation 1)

where $m$ is the total mass loading of the electrodes, $v$ is the scan rate, $E_{1}$ and $E_{2}$ are the low and high end potentials, and $I(E)$ depicts the response in current. The $C_{s}$ values are quite moderate when the SWCNT content is high which is due to the dominant capacitive response of SWCNT (typically $\sim 20{\mathrm{~F} . \mathrm{g}^{-1}}^{-15}$, $\left.{ }^{56}\right)$ over faradaic contribution of the PoPD. An increase in the PoPD content in the SWCNT/PoPD nanocomposite (from 3:1; $1: 2 ; 1: 4 ; 1: 5$ mass ratio and from 25 to $83 \mathrm{wt} \%)$ leads to an increase in the $C_{s}$ values (Figure $\mathbf{2 b}$ ).
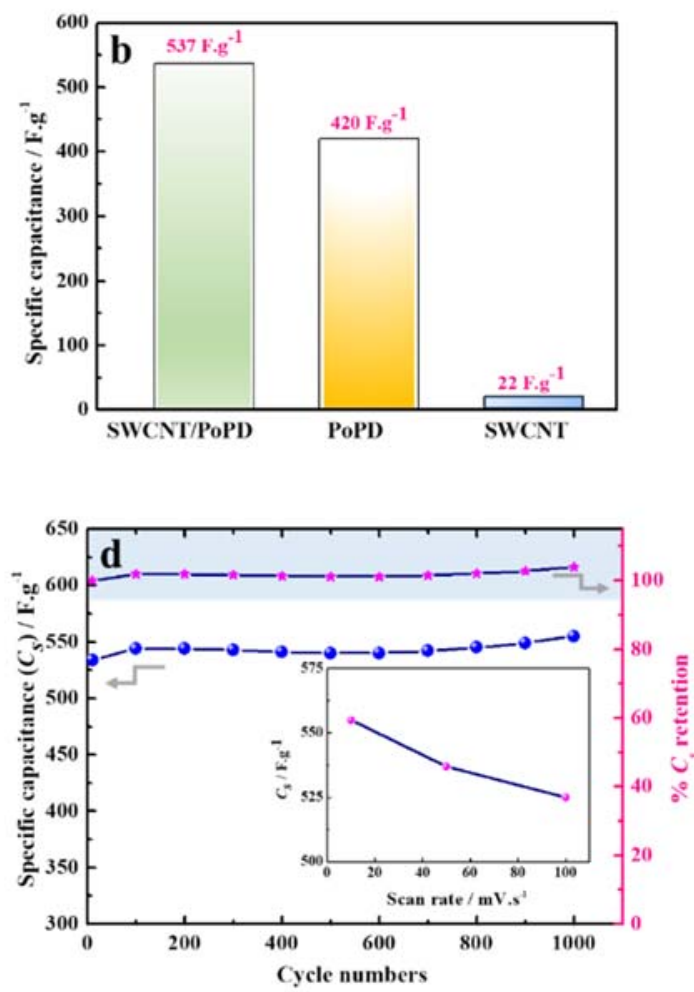

Figure 3. a) CV response of SWCNT/PoPD (1:5) nanocomposite electrode and its comparison to pristine PoPD and SWCNT counterpart (at 50 $\mathrm{mV} \cdot \mathrm{s}^{-1}$ ) where current density is normalized by the mass loading, b) the specific capacitance of pristine PoPD, SWCNT and SWCNT/PoPD (1:5) nanocomposite electrodes, c) CV response of SWCNT/PoPD (1:5) nanocomposite electrode at different scan rates and d) the specific capacitance $\left(C_{s}\right)$ measured at $50 \mathrm{mV} \cdot \mathrm{s}^{-1}$ for 1000 cycles and as a function of scan rate using the Eq. 1 (in the inset of the panel). The measurements are performed in $0.5 \mathrm{M} \mathrm{NaCl}$ at $\mathrm{pH}=2$. 
The highest $C_{s}$ value (537 F.g ${ }^{-1}$ which corresponds to an areal capacitance of $24.16 \mathrm{mF} . \mathrm{cm}^{-2}$ ) was obtained with SWCNT/PoPD (1:5) composition, which contains $\sim 17 \mathrm{wt} \%$ of SWCNT. This is in agreement with the well-defined CV response of this particular composition (Figure 2a). However, a further increase in the PoPD ratio (1:6; 1:7 ratios, Figure SI-1), i.e.; lowering the SWCNT content leads to a decrease in the $C_{s}$ values. This shows the positive impact of the SWCNT, presumably by providing higher surface area for the electropolymerization of the PoPD polymer and increasing the overall electronic conductivity of the electrode. The lower $C_{s}$ values observed for the 1:6 and 1:7 SWCNT/PoPD ratios (Figure SI-1) indicate that high PoPD content can limit the access of the electrolyte to the inner pore structure either by the formation of agglomerates or the deposition of a film over the nanocomposite, ${ }^{57}$ resulting in a drop in the $C_{s}$ value of the electrode. Thereafter, the electrochemical properties of the optimized SWCNT/PoPD with the weight ratio of 1:5 are investigated (Figure 3 ).

The electrochemical behavior of SWCNT/PoPD (1:5) nanocomposite thin films was investigated (Figure 3) using CV in three electrode cell configuration in the potential range from -0.4 to $0.7 \mathrm{~V}$ at a scan rate of $50 \mathrm{mV} \cdot \mathrm{s}^{-1}$. Figure $3 \mathrm{a}$ presents a comparison of the response of the optimized SWCNT/PoPD thin film to those of the pristine components (SWCNT and PoPD). The CV response of the SWCNT shows a typical quasirectangular shape in the potential range from -0.4 to $0.4 \mathrm{~V}$ attributed to the electric double layer capacitive behaviour. ${ }^{6}$ The PoPD electrode presents a pair of well-defined peaks, corresponding to the electrochemical redox reaction and indicating the faradaic behaviour of PoPD as a major contribution and in agreement with the earlier reports. $37,38,40$, ${ }^{54}$ For the SWCNT/PoPD (1:5) electrode, a faradaic behaviour of PoPD was also observed with an increase in current density. This can be attributed to the good synergistic effect between SWCNT and PoPD and activation of new electroactive sites due to the increase in the electronic conductivity of the nanocomposite electrode.

Figure $\mathbf{3 b}$ shows the $C_{s}$ of all the electrodes calculated from CV measurements at $50 \mathrm{mV} \cdot \mathrm{s}^{-1}$ and using the Eq. 1. Accordingly, SWCNT/PoPD (1:5) electrode exhibits the highest $C_{s}$ of about $537 \mathrm{~F} \cdot \mathrm{g}^{-1}$ compared to those of SWCNT $\left(22 \mathrm{~F} \cdot \mathrm{g}^{-1}\right)$ and PoPD $(420$ $\left.\mathrm{F} \cdot \mathrm{g}^{-1}\right)$. The enhanced electrochemical behaviour of the SWCNT/POPD (1:5) electrode is further investigated in terms of rate capability and long-term cycling performance (Figure 3c and 3d). Figure 3c shows the CV patterns of SWCNT/PoPD (1:5) nanocomposite with an increasing scan rate from 10 to 100 $\mathrm{mV} \cdot \mathrm{s}^{-1}$. The redox peak current density is higher at the higher scan rates. The redox peak separation increases with the scan rate as well, which may indicate a limitation in the chargetransfer kinetics. ${ }^{40}$ Accordingly, the $C_{s}$ of the electrode is higher at the slower scan rates but $\sim 95 \%$ of the $C_{s}$ (at $10 \mathrm{mV} \cdot \mathrm{s}^{-1}$ ) can still be obtained at $100 \mathrm{mV} \cdot \mathrm{s}^{-1}$ (inset of Figure 3d), indicating that electrolyte ions can move freely within the electrode and have sufficient time to complete the charge compensation process. ${ }^{58}$ The contributions from different charge storage mechanisms, i.e., the surface controlled or diffusion-controlled process are estimated using the $\mathrm{CV}$ curves presented in Figure 3c, applying a procedure described in the literature. ${ }^{59,60}$ Figure SI-2 demonstrates that the capacitive contribution of the SWCNT/PoPD (1:5) composite is $\sim 83 \%$ at the $100 \mathrm{mV} \cdot \mathrm{s}^{-1}$, which is much higher than that of 50 and $10 \mathrm{mV} \cdot \mathrm{s}^{-1}$ where $78 \%$ and $61 \%$ capacitive contribution are estimated, respectively. As expected, an increase in scan rate of the potential induces an increase in the capacitive contribution, since a fast adsorption/desorption process occurs at the electrode surface (Figure SI-2). ${ }^{60}$

The cycling stability of SWCNT/PoPD (1:5) electrode (loading of $45 \mu \mathrm{g} \cdot \mathrm{cm}^{-2}$ ) on gold electrode of the quartz resonator was investigated by $\mathrm{CV}$ in a three-electrode configuration in $0.5 \mathrm{M}$ $\mathrm{NaCl}$ at a scan rate of $50 \mathrm{~V} \cdot \mathrm{s}^{-1}$ (Figure 3d). It is interesting to note that SWCNT/PoPD (1:5) nanocomposite electrode exhibits not only high $C_{s}$ ( $537 \mathrm{~F} \cdot \mathrm{g}^{-1}$ corresponds to $24.16 \mathrm{mF} . \mathrm{cm}^{-2}$ ) but also excellent cycling stability (measured up to 1000 cycles) without a noticeable loss of the initial $C_{s}$.

\subsection{Investigation of the charge storage behaviour of the optimized SWCNT/PoPD nanocomposites}

In order to further appraise the cell performance, the nanocomposite electrodes with the optimized composition were prepared on the graphite substrates and tested in twoelectrode configuration by GCD measurements and compared with the responses of the SWCNT and PoPD films alone.

3.2.1. Morphological and compositional characterization of SWCNT/PoPD (1:5) film on graphite electrode: Figure 4a shows a representative FEG-SEM micrograph of the SWCNT powder, revealing a significantly high density of the CNT bundles, with diameters ranging from 5 to $20 \mathrm{~nm}$. This powder is used to prepare a slurry with PVDF-HFP binder (with 90:10 wt. \%) in NMP to drop-cast on graphite substrates. Figure $\mathbf{4 b}$ presents the TEM micrograph of the SWCNT based thin film which is obtained by scraping the substrate surface and indicates the presence of CNT bundles of 5-20 nm, in agreement with the FEG-SEM micrograph in Figure 4a. The electropolymerization of oPD monomer is performed on the SWCNT modified substrates for 1000 cycles and the FEG-SEM and TEM micrographs of the resulting nanocomposite are shown in Figure $\mathbf{4 c}$ and Figure $\mathbf{4 d}$, respectively. Contrary to the SWCNT bundle diameter of 10-20 $\mathrm{nm}$, the SWCNT/PoPD (1:5) nanocomposite is made of fibers with a larger diameter $(\sim 100-200 \mathrm{~nm})$. This observation suggests that the electropolymerization occurs around the SWCNT bundles and the latter is coated with a PoPD polymer layer, which has a thickness of $\sim 60-80 \mathrm{~nm}$. Such morphologies are previously reported where drop-cast SWCNT layers are electrochemically coated with PoPD and they are shown to be advantageous for electrochemical sensing (i.e.; voltammetric detection of colchicine) and electrocatalytic reduction of

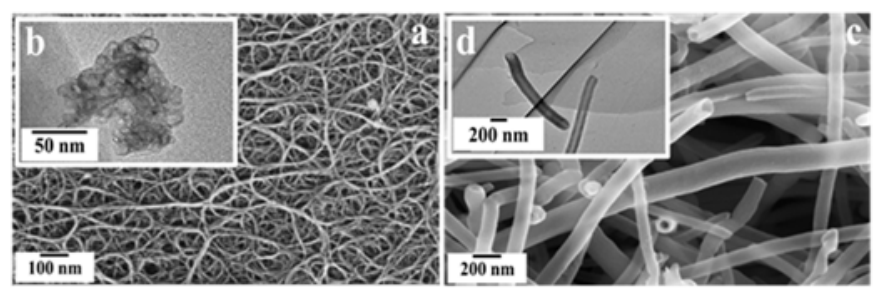

Figure 4. a) FEG-SEM micrograph of SWCNT powder, b) TEM micrograph of the SWCNT/PVDF-HFP film (90:10 wt\%) scrapped from the graphite substrate, c) FEG-SEM micrograph of SWCNT/PVDF-HFP coating on graphite electrode after 1000 electropolymerization cycles of oPD, leading to SWCNT/PoPD (1:5) electrode and d) TEM micrograph of SWCNT/POPD (1:5) scrapped from the graphite substrate. 

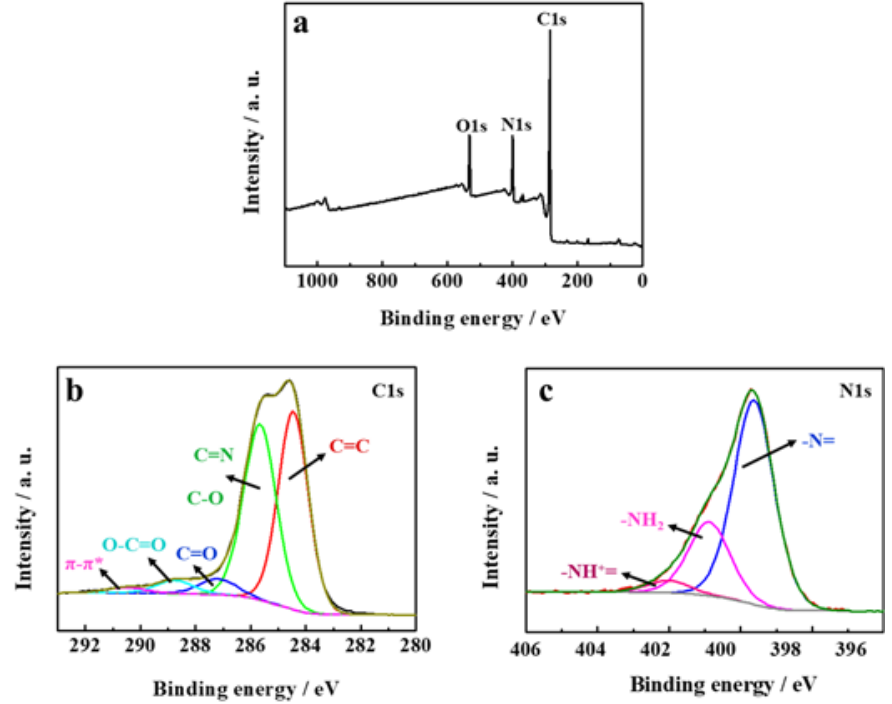

Figure 5. a) XPS survey spectrum, b) high-resolution C1s spectrum and c) high-resolution N1s spectrum of SWCNT/PoPD (1:5) nanocomposite thin film deposited on the graphite electrode.

oxygen. ${ }^{61,62}$ PEDOT coated MWCNT porous networks were also prepared by using an EDOT monomer solution containing MWCNTs, and this method also resulted in similar morphological features. ${ }^{27}$

The SWCNT/PoPD (1:5) nanocomposite is investigated by FTIR analysis and the spectra are shown in Figure SI-3 together with the assignment of the main peaks of the components (SWCNT and PoPD) summarized in Table SI-1. The peaks at 3320 and
$3190 \mathrm{~cm}^{-1}$ can be attributed to the $\mathrm{N}-\mathrm{H}$ stretching vibrations of the $-\mathrm{NH}-$ and $-\mathrm{NH}_{2}$ groups, respectively. The strong peaks at 1620 and $1530 \mathrm{~cm}^{-1}$ are assigned to $\mathrm{C}=\mathrm{N}$ and $\mathrm{C}=\mathrm{C}$ stretching vibrations in phenazine structure. ${ }^{63}$ The peaks at 1238 and 1371 $\mathrm{cm}^{-1}$ are associated with the $\mathrm{C}-\mathrm{N}$ stretching in the benzenoid and quinoid imine units. ${ }^{61} \mathrm{It}$ is noted that the chemical structure of the POPD electrodeposited on the SWCNT based electrode (Figure SI-3) is in agreement with previous reports. ${ }^{63-65}$ Thus, FTIR analysis reveals that SWCNT/PoPD (1:5) nanocomposite resembles its pristine components, i.e.; SWCNT and PoPD combining the characteristic signature of the both counterparts.

The surface chemical composition of the nanocomposite films was investigated by X-ray photoelectron spectroscopy (XPS). XPS survey spectrum of the SWCNT/PoPD (1:5) nanocomposite demonstrated the presence of $\mathrm{C}, \mathrm{O}$ and $\mathrm{N}$ elements with atomic percentages of 75, 10.2 and 14.8, respectively (Figure 5a). Highresolution spectra of $\mathrm{C}$ and $\mathrm{N}$ elements are given in Figure $\mathbf{5 b}$ and $\mathbf{5 c}$, respectively. $\mathrm{C} 1 \mathrm{~s}$ spectrum was fitted with five peaks: typically, two main contributions at $284.4 \mathrm{eV}(46.1 \%)$ and 285.7 $\mathrm{eV}(44.0 \%)$ which are assigned to $\mathrm{C}=\mathrm{C}$ and to $\mathrm{C}=\mathrm{N}$ and $\mathrm{C}-\mathrm{O}$, respectively, and three residual contributions at $287.2 \mathrm{eV}, 288.8$ $\mathrm{eV}$ and $290.5 \mathrm{eV}$ ascribed to $\mathrm{C}=\mathrm{O}$ bond, $\mathrm{O}-\mathrm{C}=\mathrm{O}$ group, and graphitic shake-up satellite peak, correspondingly. It is noted that the peak at $285.7 \mathrm{eV}$ assigned notably to $\mathrm{C}=\mathrm{N}$ confirms the presence of $\mathrm{N}$ groups in the material after the oPD electropolymerization. ${ }^{38}$ The area of the latter contribution is higher than the one solely attributed to $\mathrm{C}-\mathrm{O}$ bond for SWCNT (Figure SI-4a). Furthermore, Figure $5 c$ shows that the N1s spectrum of the nanocomposite electrode is resolved into three types of nitrogen species: $-\mathrm{N}=(399.0 \mathrm{eV} ; 69.8 \%),-\mathrm{NH}_{2}(400.4$ $\mathrm{eV} ; 25.9 \%))$, and $\left.-\mathrm{NH}^{+}=(401.6 \mathrm{eV} ; 4.3 \%)\right),{ }^{63,66-69}$ confirming the
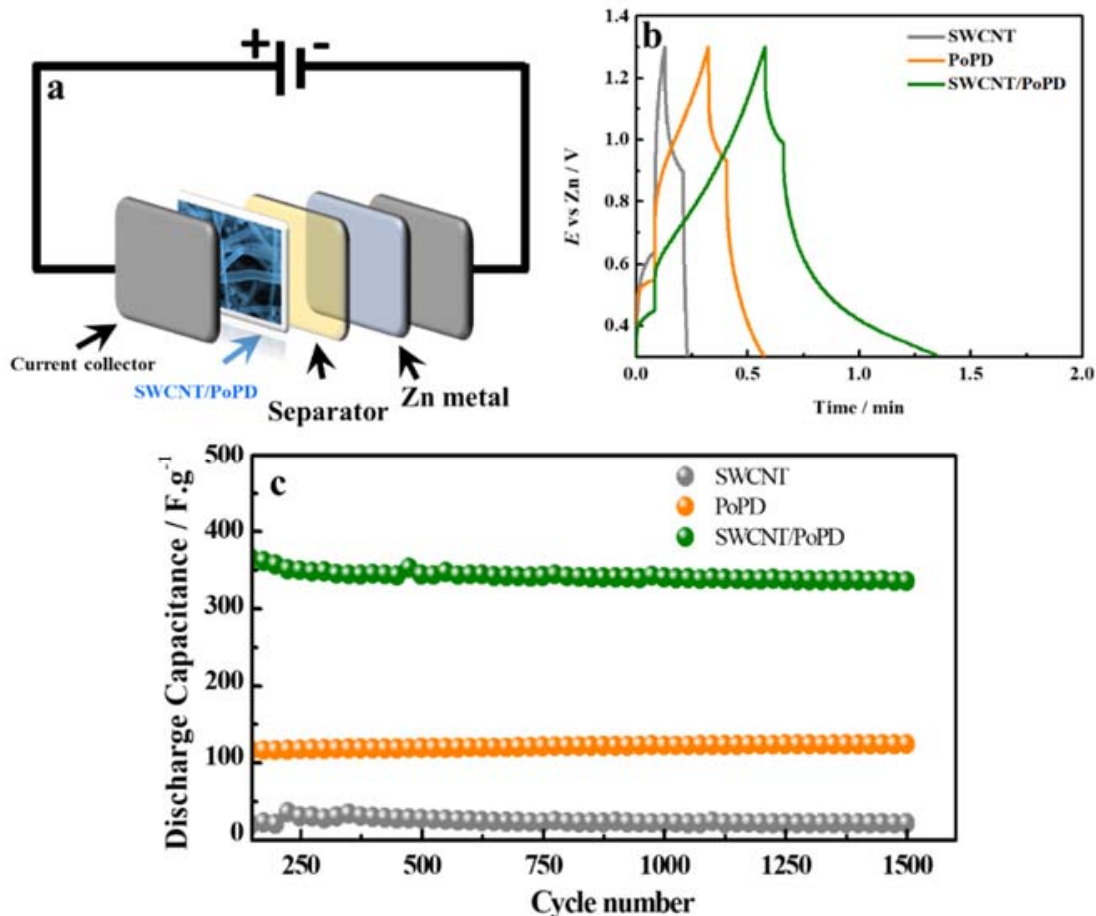

Figure 6. a) Schematic description of the 2-electrode test configuration, b) galvanostatic charge/discharge (GCD) curves of three different electrode materials (SWCNT, PoPD and SWCNT/PoPD (1:5) electrodes) at $7.3 \mathrm{~A} \cdot \mathrm{g}^{-1}\left(0.73 \mathrm{~mA} \cdot \mathrm{cm}^{-2}\right)$ presented as voltage-time graphs and at the first cycle and c) discharge capacitance as a function of cycle number for the cells. 

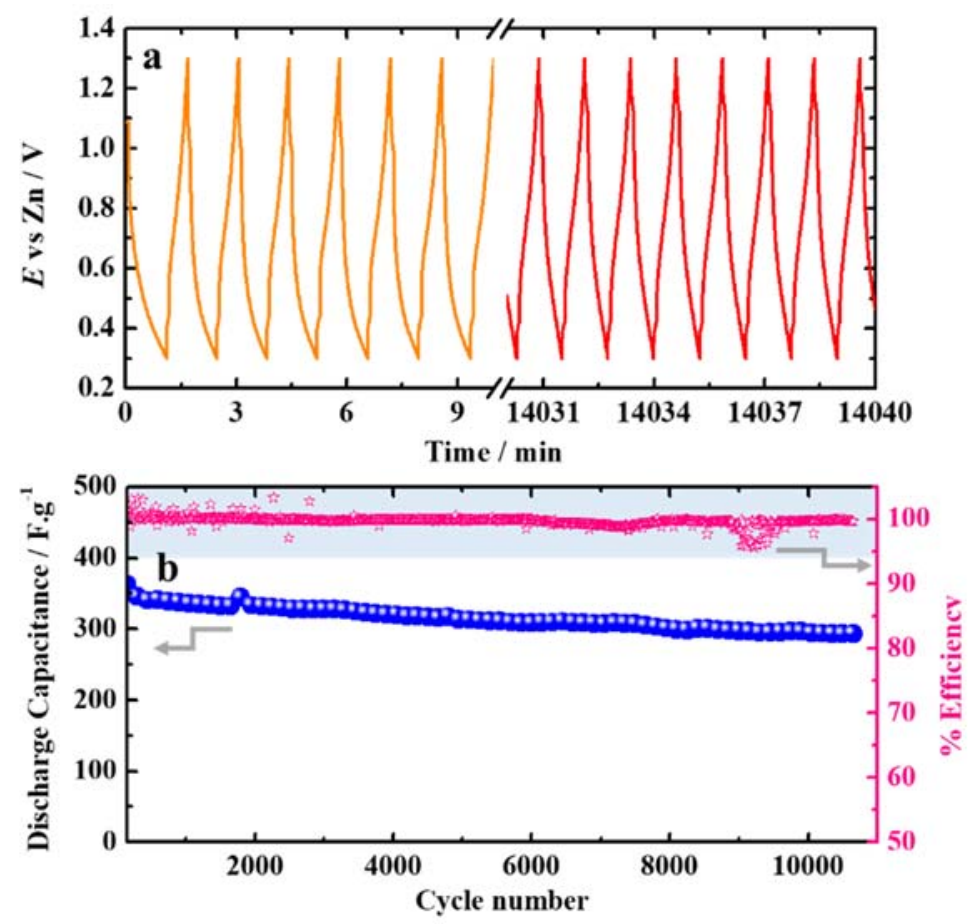

Figure 7. Galvanostatic charge/discharge (GCD) curves of the SWCNT/PoPD (1:5) electrode at $7.3 \mathrm{~A} \cdot \mathrm{g}^{-1}\left(0.73 \mathrm{~mA} \cdot \mathrm{cm}^{-2}\right)$ presented as a) voltagetime graphs and $\mathbf{b}$ ) discharge capacitance as a function of cycle number for the cell.

presence of PoPD on the SWCNT modified graphite substrate. For comparison, high-resolution spectra of $\mathrm{C} 1 \mathrm{~s}$ and N1s for PoPD pristine electrode are given in Figure $\mathbf{S I - 4 b}$ and $\mathbf{S I - 4 c}$, respectively. There are not significant differences between the N1s spectrum of the PoPD pristine electrode and that of the SWCNT/PoPD composite, in good agreement with the fact that the $\mathrm{N}$ element is only due to the PoPD component. The C1s spectrum of the SWCNT/PoPD (Figure 5b) electrode also presents similar features compared with that of PoPD (Figure $\mathbf{S I - 4 b )}$. This is in line with the observations in Figure. $\mathbf{4} \mathbf{c}$ and $\mathbf{4} \mathbf{d}$ indicating that a PoPD polymer layer with a thickness of $60-80$ $\mathrm{nm}$ was homogeneously deposited onto the CNT, and thus only PoPD layer was investigated by XPS (with an analysis depth of $10 \mathrm{~nm})$.

3.2.2. Electrochemical performance tests of SWCNT/PoPD nanocomposite in 2-electrode configuration: Figure 6 presents the galvanostatic charge-discharge (GCD) performance of the composite electrodes deposited on a graphite electrode, as well as those of their pristine counterparts. The mass loading and the thickness of the SWCNT/PoPD (1:5) electrodes are around 0.1 $\mathrm{mg} \cdot \mathrm{cm}^{-2}$ and $800 \mathrm{~nm}$, respectively. The capacitive performances of the three different electrode materials were characterized by GCD in a testing configuration described in Figure $6 \mathbf{a}$. The discharge capacitance values (at $7.3 \mathrm{~A}^{-g^{-1}}$ in a voltage window from 0.3 to $1.3 \mathrm{~V}$ vs $\mathrm{Zn}$ ) are presented as a function of cycle number in Figure 6c. The SWCNT/PoPD electrode exhibits the highest discharge capacitance value of $350 \mathrm{~F} \cdot \mathrm{g}^{-1}$, which is about 3 times higher than that of the PoPD $\left(110 \mathrm{~F} \cdot \mathrm{g}^{-1}\right)$ electrode and 30 times than that of SWCNT (12 F.g ${ }^{-1}$ ) electrode.

Moreover, all the three electrodes show an excellent stability without a significant capacity fade over 1500 cycles (Figure 6c). The electrochemical behavior of SWCNT/PoPD nanocomposite electrode which exhibits the highest discharge capacitance value among the three electrodes was further analyzed. Figure $7 \mathrm{a}$ shows the typical pseudo-capacitive behaviour attested by a non-triangular voltage-time graph. The oxidation and reduction peaks appear at around 0.95 and $0.45 \mathrm{~V}$ vs $\mathrm{Zn}$, respectively, as depicted in Figure $7 a$. These peak positions agree well with the 3-electrode measurements performed with a $\mathrm{Ag} / \mathrm{AgCl}$ reference electrode (Figure 3a) since the reference electrode potentials of $\mathrm{Ag} / \mathrm{AgCl}$ ( $v$ s SHE) is $0.197 \mathrm{~V}$ and $\mathrm{Zn}$ is -0.760 (vs SHE). The nanocomposite electrode exhibited excellent cycling performance with a discharge capacitance value of around 350 $\mathrm{F} \cdot \mathrm{g}^{-1}$ where $82 \%$ of its initial $C_{s}$ is maintained after 11000 cycles at $7.3 \mathrm{~A} \cdot \mathrm{g}^{-1}$. Furthermore, the columbic efficiency stays close to $100 \%$ over the course of 11000 cycles (Figure $\mathbf{7 b}$ ), indicating the excellent reversible electrochemical response. To highlight the improvements brought by this work with respect to previous reports on similar material combinations, the present results are compared with previously published works in the literature (Table I). Although several factors including the electrode configuration such as thickness of films and mass loading, cell components including the electrolyte salts, separator, current collectors, binders or measurement parameters affect the capacitance values, ${ }^{39,70}$ it is fair to emphasize the remarkable cycling performance and long term stability of the twoelectrode Swagelok cell shown in Figure 7. The nanocomposite electrode presents an accessible open porous network structure (Figure 4c) offering a high surface area for the electrochemical reactions and presumably a higher electrical conductivity due to the presence of the SWCNTs. Therefore, SWCNT/PoPD nanocomposite network can be considered as an interconnected porous conductive structure accessible for the electrolyte species and thus provides the benefits of both EDLC behaviour of the SWCNT and faradic contribution of the PoPD. Cycling stability of the electrodes is also verified after electrochemical tests. The FEG-SEM micrographs of the SWCNT/PoPD (1:5) electrode on graphite and Zn electrode after 


\begin{tabular}{|c|c|c|c|c|c|}
\hline $\begin{array}{c}\text { Electrode } \\
\text { material }\end{array}$ & $\begin{array}{c}\text { Specific } \\
\text { capacitance }\end{array}$ & $\begin{array}{c}\text { Electrode } \\
\text { configuration }\end{array}$ & $\begin{array}{l}\text { Synthesis } \\
\text { method }\end{array}$ & Remarks & Ref. \\
\hline PoPD & $105 \mathrm{~F} \cdot \mathrm{g}^{-1}$ at $500 \mathrm{~mA} \cdot \mathrm{g}^{-1}$ & 3-electrode & $\begin{array}{l}\text { Electrochemical } \\
\text { synthesis (with or } \\
\text { without SDS }\end{array}$ & $\begin{array}{l}82 \% \text { of capacity retention, } 1000 \\
\text { cycles, potential window }-0.2 \mathrm{~V} \text { to } \\
0.6 \mathrm{~V} \text { vs } \mathrm{SCE}^{\mathrm{b}} \text {, activated carbon as } \\
\text { counter electrode, in } 1 \mathrm{M} \mathrm{KNO}_{3}\end{array}$ & 71 \\
\hline PoPD & $8 \mathrm{~F} \cdot \mathrm{g}^{-1}$ at $0.1 \mathrm{~A} \cdot \mathrm{g}^{-1}$ & 2-electrode & $\begin{array}{l}\text { Chemical } \\
\text { polymerization }\end{array}$ & $\begin{array}{l}2000 \text { cycles, potential window } 0 \mathrm{~V} \text { to } \\
0.6 \mathrm{~V} \text {, in } 1 \mathrm{M} \mathrm{H}_{2} \mathrm{SO}_{4}\end{array}$ & 72 \\
\hline PoPD-co-aniline & $138 \mathrm{~F} \cdot \mathrm{g}^{-1}$ at $0.1 \mathrm{~A} \cdot \mathrm{g}^{-1}$ & 2-electrode & $\begin{array}{l}\text { Chemical } \\
\text { polymerization }\end{array}$ & $\begin{array}{l}65 \% \text { of capacity retention, } 2000 \\
\text { cycles, potential window } 0 \mathrm{~V} \text { to } 0.6 \\
\mathrm{~V} \text {, in } 1 \mathrm{M} \mathrm{H}_{2} \mathrm{SO}_{4}\end{array}$ & 72 \\
\hline $\begin{array}{l}\text { PpPD / } \\
\text { graphene }\end{array}$ & $248 \mathrm{~F} \cdot \mathrm{g}^{-1}$ at $2 \mathrm{~A} \cdot \mathrm{g}^{-1}$ & 2-electrode & $\begin{array}{l}\text { Chemical } \\
\text { polymerization }\end{array}$ & $\begin{array}{l}72 \% \text { of capacity retention, } 1000 \\
\text { cycles at } 10 \mathrm{~A} \cdot \mathrm{g}^{-1} \text {, potential window } \\
0 \mathrm{~V} \text { to } 1 \mathrm{~V}, \text { symmetric configuration, } \\
\text { in } 1 \mathrm{M} \mathrm{H}_{2} \mathrm{SO}_{4}\end{array}$ & 39 \\
\hline $\begin{array}{l}\text { PoPD/ } \\
\text { graphene }\end{array}$ & $\begin{array}{l}308 \mathrm{~F} \cdot \mathrm{g}^{-1} \text { at } 0.1 \mathrm{~A} \cdot \mathrm{g}^{-1} ; \\
216 \mathrm{~F} \cdot \mathrm{g}^{-1} \text { at } 1 \mathrm{~A} \cdot \mathrm{g}^{-1} ; 165 \\
\mathrm{~F} \cdot \mathrm{g}^{-1} \text { at } 5 \mathrm{~A} \cdot \mathrm{g}^{-1}\end{array}$ & 3-electrode & $\begin{array}{l}\text { Electrochemical } \\
\text { synthesis on } \mathrm{rGO}^{\mathrm{d}}\end{array}$ & 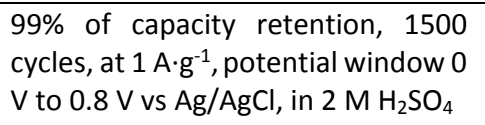 & 40 \\
\hline $\begin{array}{l}\text { Reduced } \\
\text { graphene } \\
\text { oxide/PpPD }\end{array}$ & $\begin{array}{l}347 \mathrm{~F} \cdot \mathrm{g}^{-1} \text { at } 1 \mathrm{~A} \cdot \mathrm{g}^{-1} \\
342 \mathrm{~F} \cdot \mathrm{g}^{-1} \text { at } 100 \mathrm{mV} \cdot \mathrm{s}^{-1}\end{array}$ & 3-electrode & $\begin{array}{l}\text { Chemical } \\
\text { polymerization }\end{array}$ & $\begin{array}{l}90.1 \% \text { of capacity retention, } 1000 \\
\text { cycles at } 10 \mathrm{~A} \cdot \mathrm{g}^{-1} \text {, potential window } \\
-0.2 \mathrm{~V} \text { to } 0.8 \mathrm{~V} \text { vs SCE, in } 0.5 \mathrm{M} \mathrm{H}_{2} \mathrm{SO}_{4}\end{array}$ & 41 \\
\hline r-GO-a-PoPD & $\begin{array}{l}381 \mathrm{~F} \cdot \mathrm{g}^{-1} \text { at } 1 \mathrm{~A} \cdot \mathrm{g}^{-1} \text { and } \\
329 \mathrm{~F} \cdot \mathrm{g}^{-} \text {at } 5 \mathrm{~A} \cdot \mathrm{g}^{-1}\end{array}$ & 2-electrode & $\begin{array}{l}\text { Chemical } \\
\text { polymerization }\end{array}$ & 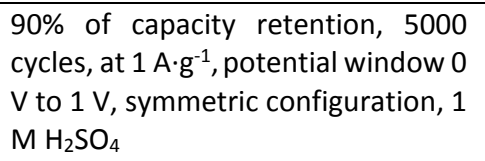 & 38 \\
\hline $\begin{array}{l}\mathrm{MnO}_{2} / \\
\mathrm{PoPD}\end{array}$ & $220 \mathrm{~F} \cdot \mathrm{g}^{-1}$ at $0.5 \mathrm{~A} \cdot \mathrm{g}^{-1}$ & 2-electrode & $\begin{array}{l}\text { Chemical } \\
\text { polymerization }\end{array}$ & $\begin{array}{l}84 \% \text { of capacity retention, } 1000 \\
\text { cycles, at } 0.5 \mathrm{~A} \cdot \mathrm{g}^{-1} \text {, potential window } \\
0.1 \mathrm{~V} \text { to } 0.9 \mathrm{~V} \text { vs } \mathrm{SCE}^{\mathrm{b}} \text {, activated } \\
\text { carbon as counter electrode, in } 1 \mathrm{M} \\
\mathrm{KNO}_{3}\end{array}$ & 73 \\
\hline $\begin{array}{l}\text { PoPD/ } \\
\text { SWCNT }\end{array}$ & $\begin{array}{l}350 \mathrm{~F} \cdot \mathrm{g}^{-1} \text { at } 7.3 \mathrm{~A} \cdot \mathrm{g}^{-1} \\
\text { (2-electrode) } \\
540 \mathrm{~F} \cdot \mathrm{g}^{-1} \text { at } 50 \mathrm{mV} \cdot \mathrm{s}^{-1} \\
\text { (3-electrode) }\end{array}$ & $\begin{array}{l}\text { 2-electrode and } \\
\text { 3-electrode }\end{array}$ & $\begin{array}{l}\text { Electrochemical } \\
\text { synthesis on } \\
\text { SWCNT }\end{array}$ & $\begin{array}{l}82 \% \text { of capacity retention, } 11000 \\
\text { cycles, at } 7.3 \mathrm{~A} \cdot \mathrm{g}^{-1} \text {, potential window } \\
0.3 \mathrm{~V} \text { to } 1.1 \mathrm{~V} \text { vs } \mathrm{Zn} \text {, asymmetric } \\
\text { configuration, } 0.5 \mathrm{M} \mathrm{NaCl}\end{array}$ & $\begin{array}{l}\text { This } \\
\text { work }\end{array}$ \\
\hline
\end{tabular}

aSDS: sodium dodecyl sulphate, bSCE: Saturated calomel electrode, 'PpPD: Poly(para-phenylenediamine), drGO: reduced graphene oxide

cycling are provided in Figure SI-5a, $\mathbf{b}$ and $\mathbf{d}$. These micrographs are compared with those of the fresh electrodes in Figure 4c and Figure SI-5c, for SWCNT/PoPD (1:5) and Zn, respectively. No significant morphological changes were observed even after 11000 cycles, except the presence of residual glass fibers originating from the separator used in the Swagelok tests (identified by the EDX analysis shown in Figure SI-5a, b and d), further attesting of the cycling stability of the SWCNT/PoPD (1:5) and $\mathrm{Zn}$ electrode under the present experimental conditions.

\section{Conclusions}

We demonstrate the potential of the SWCNT/PoPD nanocomposite materials to enhance the performance of the pristine PoPD electrodes for energy storage applications. Several compositions were prepared ranging from 25 to $87.5 \mathrm{wt} \%$ of PoPD incorporated in the final nanocomposites and such precise compositions were defined by means of a QCM study. The resulting electrodes with various compositions were electrochemically tested among which 1:5 weight ratio ( $83 \mathrm{wt} \%$ of PoPD) (SWCNT/PoPD) delivered an optimum charge storage performance. This observation is attributed to a good balance between the ameliorated electron percolation in the nanocomposite benefiting from the underlying SWCNT network and the additional pseudocapacitance provided by the overlaid PoPD. The compositional characteristics optimized in the first part of the study were used as a base for the preparation of electrodes to be tested in two-electrode Swagelok cells. SWCNT/PoPD (1:5) electrodes were tested as cathodes where $\mathrm{Zn}$ metal was used as negative electrode in an aqueous electrolyte. The cell exhibits areal capacitance of $35 \mathrm{mF} \cdot \mathrm{cm}^{-2}$ at $0.73 \mathrm{~mA} \cdot \mathrm{cm}^{-2}$ and gravimetric capacitance of $350 \mathrm{~F} \cdot \mathrm{g}^{-1}$ at a current density of $7.3 \mathrm{~A} \cdot \mathrm{g}^{-1}$, as well as long lifetime of more than 11000 cycles. These composite materials are significant for developing high-performance microsupercapacitors and also show the potential perspective of the conducting polymer based nanocomposite electrodes for miniaturized electronics. The proposed device structure itself is highly promising, may provide a new concept for developing hybrid 
micro-energy storage system with a capacitor-type cathode and a battery-type anode, employing multivalent charge carrier such as $\mathrm{Zn}^{2+}$.

\section{Conflicts of interest}

"There are no conflicts to declare".

\section{Acknowledgements}

The authors thank Mrs. Stéphanie Delbrel and Mrs. Françoise Pillier for FEG-SEM analysis (LISE, UMR8235, Sorbonne University, France).

\section{Notes and references}

1. A. Borenstein, O. Hanna, R. Attias, S. Luski, T. Brousse and D. Aurbach, J. Mater. Chem. A, 2017, 5, 12653-12672.

2. H. Shao, Y.-C. Wu, Z. Lin, P.-L. Taberna and P. Simon, Chem. Soc. Rev., 2020, 49, 3005-3039.

3. R. Demir-Cakan, M. R. Palacín and L. Croguennec, J. Mater. Chem. A, 2019, 7, 20519-20539.

4. P. Simon and Y. Gogotsi, Nat. Mater., 2020, 19, 1151-1163.

5. F. Béguin, V. Presser, A. Balducci and E. Frackowiak, Adv. Mater., 2014, 26, 2219-2251.

6. P. Simon and Y. Gogotsi, Acc. Chem. Res., 2013, 46, 10941103.

7. Q. C. Zhang, Z. Y. Zhou, Z. H. Pan, J. Sun, B. He, Q. L. Li, T. Zhang, J. X. Zhao, L. Tang, Z. X. Zhang, L. Wei and Y. G. Yao, Adv. Science, 2018, 5, 1801462.

8. C. Lin, L. Hu, C. Cheng, K. Sun, X. Guo, Q. Shao, J. Li, N. Wang and Z. Guo, Electrochim. Acta, 2018, 260, 65-72.

9. Y. X. Bai, B. Y. Shen, S. L. Zhang, Z. X. Zhu, S. L. Sun, J. Gao, B. H. Li, Y. Wang, R. F. Zhang and F. Wei, Adv. Mater., 2019, 31.

10. J. W. Baur, D. J. Hartl, G. J. Frank, G. Huff, K. A. Slinker, C. Kondash, W. Joshua Kennedy and G. J. Ehlert, in Mechanics of Composite and Multi-functional Materials, Volume 6, eds. P. R. Thakre, R. Singh and G. Slipher, Springer International Publishing, Cham, 2018, pp. 215-221.

11. S. Fleischmann, J. B. Mitchell, R. Wang, C. Zhan, D.-e. Jiang, V. Presser and V. Augustyn, Chem. Rev., 2020, 120, 6738-6782.

12. G. A. Snook, P. Kao and A. S. Best, J. Power Sources, 2011, 196, $1-12$.

13. Q. Meng, K. Cai, Y. Chen and L. Chen, Nano Energy, 2017, 36, 268-285.

14. T. Liu, L. Finn, M. Yu, H. Wang, T. Zhai, X. Lu, Y. Tong and Y. Li, Nano Lett., 2014, 14, 2522-2527.

15. A. M. Bryan, L. M. Santino, Y. Lu, S. Acharya and J. M. D'Arcy, Chem. Mater., 2016, 28, 5989-5998.

16. S. H. Patil, A. P. Gaikwad, S. D. Sathaye and K. R. Patil, Electrochim. Acta, 2018, 265, 556-568.

17. K. L. Zhou, H. Wang, J. T. Jiu, J. B. Liu, H. Yan and K. Suganuma, Chem. Eng. J., 2018, 345, 290-299.

18. S. S. Shinde, G. S. Gund, D. P. Dubal, S. B. Jambure and C. D. Lokhande, Electrochim. Acta, 2014, 119, 1-10.

19. E. Karaca, N. O. Pekmez and K. Pekmez, Electrochim. Acta, 2014, 147, 545-556.

20. L. Chen, D. P. Li, L. N. Chen, P. C. Si, J. K. Feng, L. Zhang, Y. H. Li, J. Lou and L. J. Ci, Carbon, 2018, 138, 264-270.

21. Z.-H. Chang, D.-Y. Feng, Z.-H. Huang and X.-X. Liu, Chem. Eng. J., 2018, 337, 552-559.
22. Y. Han, P. Chen, Y. Xia, S. Huang, W. Chen and W. Lu, J. Solid State Electrochem., 2019, 23, 1553-1562.

23. J.-h. Liu, X.-y. Xu, J. Yu, J.-I. Hong, C. Liu, X. Ouyang, S. Lei, X. Meng, J.-N. Tang and D.-Z. Chen, Electrochim. Acta, 2019, 314, 9-19.

24. B. Che, H. Li, D. Zhou, Y. Zhang, Z. Zeng, C. Zhao, C. He, E. Liu and X. Lu, Composites Part B: Engineering, 2019, 165, 671678.

25. S. Zeng, H. Chen, F. Cai, Y. Kang, M. Chen and Q. Li, J. Mater. Chem. A, 2015, 3, 23864-23870.

26. R. Malik, L. Zhang, C. McConnell, M. Schott, Y.-Y. Hsieh, R. Noga, N. T. Alvarez and V. Shanov, Carbon, 2017, 116, 579590.

27. M. Tahir, L. He, W. A. Haider, W. Yang, X. Hong, Y. Guo, X. Pan, H. Tang, Y. Li and L. Mai, Nanoscale, 2019, 11, 7761-7770.

28. X. He, W. Yang, X. Mao, L. Xu, Y. Zhou, Y. Chen, Y. Zhao, Y. Yang and J. Xu, J. Power Sources, 2018, 376, 138-146.

29. R. Soni, S. N. Bhange, E. Athira, R. Chetry and S. Kurungot, ChemElectroChem, 2019, 6, 1861-1869.

30. O. Y. Posudievsky, O. A. Kozarenko, V. S. Dyadyun, I. E. Kotenko, V. G. Koshechko and V. D. Pokhodenko, J. Solid State Electrochem., 2018, 22, 3419-3430.

31. J. Luo, Q. Ma, H. Gu, Y. Zheng and X. Liu, Electrochim. Acta, 2015, 173, 184-192.

32. S. U. Muhamad, N. H. Idris and M. F. M. Din, Int. J. Electrochem. Sci., 2019, 14, 6920-6937.

33. S. K. Kandasamy and K. Kandasamy, Int. J. Electrochem. Sci., 2019, 14, 4718-4729.

34. F. N. Indah Sari and J.-M. Ting, Electrochim. Acta, 2019, 320, 134533.

35. J. Cherusseri and K. K. Kar, J. Mater. Chem. A, 2016, 4, 99109922.

36. H.-P. Cong, X.-C. Ren, P. Wang and S.-H. Yu, Energy Environ. Sci., 2013, 6, 1185-1191.

37. W. Deng, Y. Zhang, Y. Tan and M. Ma, J. Electroanal. Chem., 2017, 787, 103-109.

38. W. Yang, H. Zhou, Z. Huang, H. Li, C. Fu, L. Chen, M. Li, S. Liu and Y. Kuang, Electrochim. Acta, 2017, 245, 41-50.

39. Jaidev and S. Ramaprabhu, J. Mater. Chem., 2012, 22, 1877518783.

40. H. Yadegari, H. Heli and A. Jabbari, J. Solid State Electrochem., 2013, 17, 2203-2212.

41. Z. Liu, H. Zhou, Z. Huang, W. Wang, F. Zeng and Y. Kuang, J. Mater. Chem. A, 2013, 1, 3454-3462.

42. H. Xu, X. H. Yan, Z. W. Meng, T. Xue, D. Li, G. L. Fang and H. F. Shen, Mater. Res. Express, 2019, 6.

43. E. M. Halim, R. Demir-Cakan, H. Perrot, M. El Rhazi and O. Sel, J. Power Sources, 2019, 438, 227032.

44. H. Zhang, Y. Cao, M. O. L. Chee, P. Dong, M. Ye and J. Shen, Nanoscale, 2019, 11, 5807-5821.

45. J. Li, A. Levitt, N. Kurra, K. Juan, N. Noriega, X. Xiao, X. Wang, H. Wang, H. N. Alshareef and Y. Gogotsi, Energy Stor. Mater., 2019, 20, 455-461.

46. P. P. Zhang, Y. Li, G. Wang, F. X. Wang, S. Yang, F. Zhu, X. D. Zhuang, O. G. Schmidt and X. L. Feng, Adv. Mater., 2019, 31.

47. S. Zhang, S. Long, H. Li and Q. Xu, Chem. Eng. J., 2020, 400, 125898.

48. F. Escobar-Teran, H. Perrot and O. Sel, J. Phys. Chem. C, 2019, 123, 4262-4273.

49. F. Escobar-Teran, A. Arnau, J. V. Garcia, Y. Jiménez, H. Perrot and O. Sel, Electrochem. Commun., 2016, 70, 73-77.

50. G. Sauerbrey, Zeitschrift für Physik, 1959, 155, 206-222.

51. K. Bizet, C. Gabrielli and H. Perrot, Appl. Biochem. Biotechnol., 2000, 89, 139. 
52. D. A. Shirley, Phys. Rev. B, 1972, 5, 4709-4714.

53. K. Martinusz, E. Czirók and G. Inzelt, J. Electroanal. Chem., 1994, 379, 437-444.

54. X. H. Zhang, S. M. Wang, J. Wu and X. J. Liu, J. Appl. Polym. Sci., 2007, 104, 1928-1932.

55. F. Escobar-Teran, H. Perrot and O. Sel, Electrochim. Acta, 2018, 271, 297-304.

56. H. Pan, J. Y. Li and Y. P. Feng, Nanoscale Res. Lett., 2010, 5, 654-668.

57. V. Gupta and N. Miura, Electrochim. Acta, 2006, 52, 17211726.

58. S. Al-Rubaye, R. Rajagopalan, S. X. Dou and Z. Cheng, J. Mater. Chem. A, 2017, 5, 18989-18997.

59. J. Wang, J. Polleux, J. Lim and B. Dunn, J. Phys. Chem. C, 2007, 111, 14925-14931.

60. Y. Chen, L. Qin, Y. Lei, X. Li, J. Dong, D. Zhai, B. Li and F. Kang, ACS Appl. Mater.Inter., 2019, 11, 45578-45585.

61. X. H. Zhang, S. M. Wang, L. Jia, Z. X. Xu and Y. Zeng, Sens. Actuator B-Chem., 2008, 134, 477-482.

62. P. Gajendran and R. Saraswathi, J. Phys. Chem. C, 2007, 111, 11320-11328.

63. J.-F. Feng, T. Sun and J. Zhu, Synth. Met., 2016, 213, 12-17.

64. X.-G. Li, X.-L. Ma, J. Sun and M.-R. Huang, Langmuir, 2009, 25, 1675-1684.

65. F. Liao, S. Yang, X. Li, L. Yang, Z. Xie, C. Hu, S. Yan, T. Ren and Z. Liu, Synth. Met., 2014, 189, 126-134.

66. H. Zhu, X. L. Wang, X. X. Liu and X. R. Yang, Adv. Mater., 2012, 24, 6524-6529.

67. L. Yang, Z. Li, G. Nie, Z. Zhang, X. Lu and C. Wang, Appl. Surf. Sci., 2014, 307, 601-607.

68. T. Siva, K. Kamaraj, V. Karpakam and S. Sathiyanarayanan, Prog. Org. Coat., 2013, 76, 581-588.

69. S. Yan, S. W. Yang, L. He, C. C. Ye, X. Song and F. Liao, Synth. Met., 2014, 198, 142-149.

70. M. D. Stoller and R. S. Ruoff, Energy Environ. Sci., 2010, 3, 1294-1301.

71. M. Wang, H. Zhang, C. Wang, X. Hu and G. Wang, Electrochim. Acta, 2013, 91, 144-151.

72. J. L. Olmedo-Martinez, B. I. Farias-Mancilla, A. Vega-Rios and E. A. Zaragoza-Contreras, J. Power Sources, 2017, 366, 233240.

73. M. Wang, H. Zhang, C. Wang and G. Wang, Electrochim. Acta, 2013, 106, 301-306. 